\title{
VARIASI VARIABEL PENGARUH FIX DAN RANDOM TERHADAP PRODUKSI GULA DAN TETES
}

\author{
I Nyoman Latra \\ Jurusan Statistika FMIPA-ITS Surabaya \\ Email : i_nyoman_l@statistika.its.ac.id \\ Nur Iriawan, Purhadi, dan Suhartono \\ Jurusan Statistika FMIPA-ITS Surabaya
}

\begin{abstract}
This paper presents the modeling of the amount of sugar and molasses production in Pabrik Gula Candi Baru Sidoarjo (PGCBS), East.Java, by using multivariate mixed linear models. Estimation of parameters will be done by using maximum likelihood coupled with restricted maximum likelihood methods. The amount of sugar and molasses products which have strong linear correlation, will be set as responses and are supposed to be affected by seven fixed effect variables and four random effect variables. This paper demonstrates that the seven fixed effect variables and only one random effect variable have significant influence on a single response. In the multivariate response modeling, however. all of variables fail to explain the variability of these two responses simultaneously. It is due to the factors matrix has no fill rank. As a result, the model response of molasses can be explained by using a model of the amount of sugar obtained.
\end{abstract}

Keywords: Linear mixed models, Multivariate linear models, Maximum likelihood, Asymptotic normality and efficiency, Consistency.

ABSTRAK: Makalah ini menyajikan pemodelan data jumlah gula dan tetes di Pabrik Gula Candi Baru Sidoarjo (PGCBS), Jawa Timur dengan menggunakan model linear campuran multivariate. Pendugaan parameter dalam pemodelan ini akan dilakukan dengan menggunakan penggabungan metode maksimum likelihood dan maksimum likelihood terbatas. Jumlah gula dan tetes sebagai dua produk dari PGCBS yang terbukti mempunyai hubungan linear sangat kuat akan diposisikan sebagai respon model yang dicurigai dipengaruhi oleh tujuh variabel tetap dan empat variabel random. Hasil pemodelan menunjukkan bahwa ketujuh variabel tetap dan hanya satu variabel random saja yang berpengaruh secara signifikan pada respon tunggal. Sedangkan untuk respon multivariate, pemodelan tidak bisa memberikan keputusan signifikansi setiap variabel yang dicurigai berpengaruh, karena rank matriks faktornya tidak penuh. Akibatnya, model respon jumlah tetes dapat dijelaskan menggumakan model jumlah gula yang diperoleh.

Kata kunci: Model linier campuran, Model linier multivariat, Maksimum likelihood, Normal dan efisien asimptotis, Konsisten. 


\section{PENDAhuluan}

Para statistikawan dan pengguna statistik sering mengalami kesulitan dalam menganalisis ukuran-ukuran kelompok atau ulangan yang biasanya diakibatkan oleh adanya korelasi antar pengamatan pada subjek yang sama atau dalam kelompok yang sama. Dalam kasus perolehan hasil ganda (multiple outcomes) dua jenis korelasi yang harus diperhatikan adalah korelasi antar pengukuran pada variabel yang berbeda dan korelasi antar pengukuran pada variabel yang sama dalam kelompok atau subjek. Garson (2008) menjelaskan bahwa Model Linier Campuran menangani data dengan pengamatan yang tidak bebas atau model dengan error yang berkorelasi. Ada beberapa istilah yang digunakan pada Model Linier Campuran antara lain: (1) pengaruh random, (2) pengaruh hirarkhi, (3) pengaruh fixed.

Banyak peneliti telah mempublikasikan karyanya yang berkaitan dengan model linier campuran univariat antara lain: Morrell, Pearson, dan Brant (1997), LaMotte (2007), Searle (1997), Picard, Lebarbier, Budinska, dan Robin (2007). Sedangkan ada beberapa tulisan yang berkaitan dengan kasus-kasus multivariat campuran dalam respons seperti: Sammel, Ryan, dan Legler (1997), Edward dan Allenby (2003), serta Samani dan Ganjali (2008).

Peneliti yang menampilkan karyanya dalam model linier campuran multivariat dimana campuran ada pada kovariat yaitu bagian fix dan bagian random antara lain: Kalaian dan Raudenbush (1996), Kubokawa dan Srivastava (2002), serta Schafer dan Yucel (2002). Gupta, Harrar, dan Fujikoshi (2006) mengambil masalah penurunan distribusi asimptotis dari tiga yang biasa dipakai pada statistik uji multivariat, yaitu statistik : rasio likelihood, Lawley-Hotelling, dan Bartlet-NandaPillai. Pan dan MacKenzie (2007) memberikan metode data-driven untuk pemodelan bersyarat, melakukan re-analisis data ternak Kenward dan studi simulasi.

Dari beberapa hasil terapan model linier campuran multivariat di atas, penulis bermaksud melakukan penelitian dengan menerapkan model linier campuran multivariat pada proses produksi gula dan tetes di Pabrik Gula Candi Baru, Sidoarjo, Jawa Timur. 
Kontribusi penelitian yang diharapkan adalah menambah dan mengangkat kemampuan analisis dalam bidang ilmu statistika, khususnya terapan model linier campuran multivariat pada industri gula dan tetes.

\section{METODE PENELITIAN}

Data penelitian merupakan data sekunder yang bersumber dari hasil panen tebu dan proses giling untuk periode tahun 2009 di pabrik gula Candi Baru Sidoarjo Jawa Timur. Dalam periode itu pabrik gula Candi Baru Sidoarjo melakukan proses giling selama 180 hari penuh dengan periode laporan sebanyak 12 yaitu setiap pertengahan bulan (tanggal 15) dan setiap akhir bulan (tanggal 30 atau tanggal 31).

\subsection{Bahan}

Bahan penelitian yang dimaksud adalah bahan yang digunakan dalam proses produksi gula dan tetes yang dapat dikelompokkan atas dua macam yaitu: bahan utama dan bahan penunjang.

a) Bahan utama: Tebu (Sacharum Officinarum)

Publikasi dari Revitalisasi Pertanian, Perikanan, dan Kehutanan (2009) menjelaskan bahwa tebu termasuk keluarga rumput-rumputan (Graminae) dan berkembang biak di daerah beriklim udara sedang sampai panas. Setiap jenis tebu mempunyai ukuran batang serta warna yang berlainan. Tinggi batang berkisar antara 2-4 meter dengan banyak ruas yang dipisahkan oleh buku-buku.

Data tebu yang tersedia di Pabrik Gula Candi Baru Sidoarjo (PGCBS) adalah data dari tatakelola lahan termasuk jenisnya yaitu kerja sama usaha yang dikelola oleh PGCBS atau petani, lahan diolah secara mandiri oleh petani, jenis lahan berupa sawah atau tegal, pola tebang-tanam berupa tanaman baru atau keprasan.

b) Bahan Penunjang : Kapur Tohor, Belerang, Asam Phosphat, dan Air Imbibisi.

\subsection{Alat (Stasiun) Produksi}

Alat penelitian yang dimaksud adalah alat yang digunakan dalam proses produksi gula dan tetes yang lebih dikenal dengan sebutan stasiun-stasiun yaitu: 
Stasiun Gilingan (Mill Tandem), Stasiun Pemurnian Nira, Stasiun Penguapan, Stasiun Masakan, Stasiun Puteran, dan Stasiun Ketel (Ratmanto, 2008).

\subsection{Identifikasi Variabel}

Variabel penelitian diidentifikasi dan dikelompokkan sebagai berikut;

Variabel respons diambil dari hasil produksi yaitu:

$\mathrm{Y} 1=$ "berat gula yang dihasilkan dalam kwintal", dan

$\mathrm{Y} 2$ = "berat tetes yang dihasilkan dalam kwintal".

Variabel penjelas pengaruh fix diambil dari jenis dan tata cara pengelolaan lahan baik yang memanfaatkan dana Keridit Ketahanan Pangan (KKP) maupun yang tidak (dalam kwintal):

ATRSI = "variasi berat tebu rakyat kerja sama usaha dengan jaminan pendapatan minimum bagi petani, lahan sawah pengelola PGCBS untuk tanaman baru",

ATRSII = "variasi berat tebu rakyat kerja sama usaha dengan jaminan pendapatan minimum bagi petani, lahan sawah pengelola PGCBS untuk tanaman keprasan)",

BIBIT = "variasi berat tebu untuk bibit lahan sawah pengelola PGCBS",

BTRSI = "variasi berat tebu rakyat kerja sama usaha, lahan sawah pengelola petani untuk tanaman baru",

BTRSII = "variasi berat tebu rakyat kerja sama usaha, lahan sawah pengelola petani untuk tanaman keprasan",

BTRTI = "variasi berat tebu rakyat kerja sama usaha, lahan tegal pengelola petani untuk tanaman baru",

BTRTII = "variasi berat tebu rakyat kerja sama usaha, lahan tegal pengelola petani untuk tanaman keprasan",

TRM = "variasi berat tebu rakyat kerja mandiri"

TOGIL = "variasi berat total tebu giling" (optional).

Sedangkan untuk variabel penjelas pengaruh random diambil dari bahan-bahan penunjang yaitu: 
IMBI = "variasi berat air imbibisi" (dalam kwintal).

KT = "variasi berat kapur tohor" (dalam kilogram).

BEL = "variasi berat belerang" (dalam kilogram).

$\mathrm{AP} \quad=$ "variasi volume asam phosphat" (dalam liter).

\subsection{Langkah Analisis}

Urutan langkah analisis penelitian adalah sebagai berikut:

a) Edit data dengan membuat matriks korelasi secara keseluruhan.

b) Melakukan pemeriksaan dan pengujian atas asumsi kenormalan multivariat data variabel respons dengan bantuan Q-Q plot dan statistik uji ukuran skewness dan kurtosis multivariatnya Mardia apakah variabel respons memenuhi kriteria berdistribusi normal multivariat atau harus lewat pendekatan normal multivariat asimptotis.

c) Membuang (tidak mengikutkan dalam proses analisis) pengamatan yang outlier (terpencil).

d) Menghitung (menyesuaikan) matriks-matriks yang diperlukan dalam proses analisis multivariat.

e) Melakukan perhitungan dugaan parameter model linier campuran multivariat.

f) Melakukan perhitungan untuk pengujian hipotesis terhadap parameter model linier campuran multivariat.

g) Melakukan analisis hasil yang diperoleh serta menarik kesimpulan.

\section{HASIL DAN PEMBAHASAN}

Dalam bab ini pembahasan akan dimulai dengan seleksi awal variabel berdasarkan atas model yang sudah ditetapkan apakah data sudah sesuai atau layak bagi model, pemeriksaan asumsi yang diperlukan model, pendugaan parameter model, dan pembahasan hasil yang diperoleh.

\subsection{Seleksi Awal Variabel}

Model yang diterapkan pada hasil produksi Gula dan Tetes di Pabrik Gula Candi Baru, Kabupaten Sidoarjo Jawa Timur adalah model linier campuran 
multivariat, $\mathbf{Y}=\mathbf{X B}+\mathbf{Z D}+\mathbf{E}$ melibatkan sebanyak 15 variabel yang terdiri atas: dua variabel respons datanya termuat dalam matriks $\mathbf{Y}=\left[\begin{array}{ll}\mathbf{y}_{1} & \mathbf{y}_{2}\end{array}\right]$ dengan $\mathbf{y}_{1}$ untuk variabel Y1 dan $y_{2}$ untuk variabel Y2. Selanjutnya ada sebanyak sembilan variabel penjelas pengaruh fix yang diambil dari jenis dan tatacara pengelolaan lahan tebu baik yang memanfaatkan dana Kredit Ketahanan Pangan (KKP) maupun yang tidak, termuat dalam matriks $\mathbf{X}=\left[\begin{array}{lllllllll}\mathbf{x}_{1} & \mathbf{x}_{2} & \mathbf{x}_{3} & \mathbf{x}_{4} & \mathbf{x}_{5} & \mathbf{x}_{6} & \mathbf{x}_{7} & \mathbf{x}_{8} & \mathbf{x}_{9}\end{array}\right]$, dengan $\mathbf{x}_{1}$ untuk variabel ATRSI, $x_{2}$ untuk variabel ATRSII, $x_{3}$ untuk variabel BIBIT, $x_{4}$ untuk variabel BTRSI, $\mathbf{x}_{5}$ untuk variabel BTRSII, $\mathbf{x}_{6}$ untuk variabel BTRTI, $\mathbf{x}_{7}$ untuk variabel BTRTII, $\mathbf{x}_{8}$ untuk variabel TRM, $\mathbf{x}_{9}$ untuk variabel TOGIL dan sisanya ada sebanyak empat variabel penjelas pengaruh random termuat dalam matriks $\mathbf{Z}=\left[\begin{array}{llll}\mathbf{z}_{1} & \mathbf{z}_{2} & \mathbf{z}_{3} & \mathbf{z}_{4}\end{array}\right]$, dengan $\mathbf{z}_{1}$ untuk variabel IMBI, $\mathbf{z}_{2}$ untuk variabel $\mathrm{KT}, \mathbf{z}_{3}$ untuk variabel BEL, $\mathbf{z}_{4}$ untuk variabel AP. Total pengamatan yang diambil sebanyak 171 hari.

Dalam seleksi awal kelayakan variabel dilakukan dengan menggunakan logika dan korelasi. Secara logika variabel Total Tebu Giling (TOGIL) dan variabel Air Imbibisi (IMBI) dicanangkan untuk tidak diikutkan dalam analisis karena akan memberikan kolinearitas untuk TOGIL dan efek nonaditifity untuk IMBI. Namun dari hasil koefisien korelasi tidak memberikan adanya tanda-tanda seperti yang diperkirakan sebelumnya, sehingga disepakati IMBI tetap diikutkan dalam analisis sedangkan BIBIT digabung ke ATRSII karena datanya terlalu sedikit dan disesuaikan dengan sifat-sifat tatakelola lahannya. Hal ini berarti harus melakukan tranformasi variabel baru ATRSII1 $=$ ATRSII + BIBIT vektor datanya adalah $\mathbf{x}_{21}=\mathbf{x}_{\mathbf{2}}+\mathbf{x}_{\mathbf{3}}$, sehingga ukuran kolom matriks pengaruh fix termasuk intersep menjadi delapan

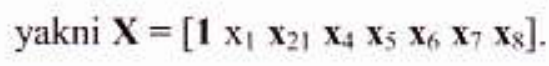

\subsection{Pemeriksaan Asumsi Kenormalan Multivariat dan Pencilan (Outlier)}

Pemeriksaan asumsi kenormalan multivariat dilakukan dengan Q-Q Plot antara Jarak Robust Mahalanobis lawan Kuantil Chi-Kuadrat dan ditunjang oleh uji hipotesis versi skewness dan versi kurtosis (Khattree dan Naik, 1999).

Q-Q Plot antara Jarak Robust Mahalanobis lawan Kuantil Chi-Kuadrat untuk data setelah melakukan seleksi awal diperlihatkan pada Gambar 1 (a). Dari Gambar 


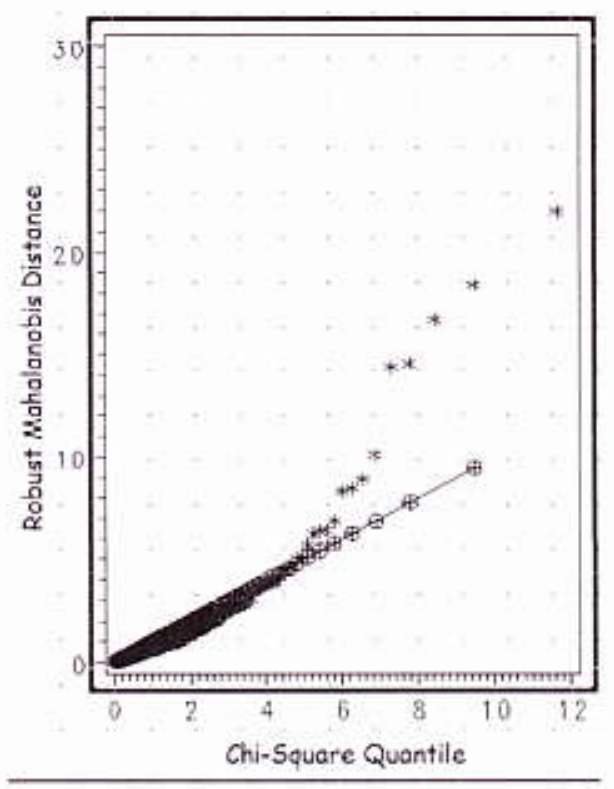

(a)

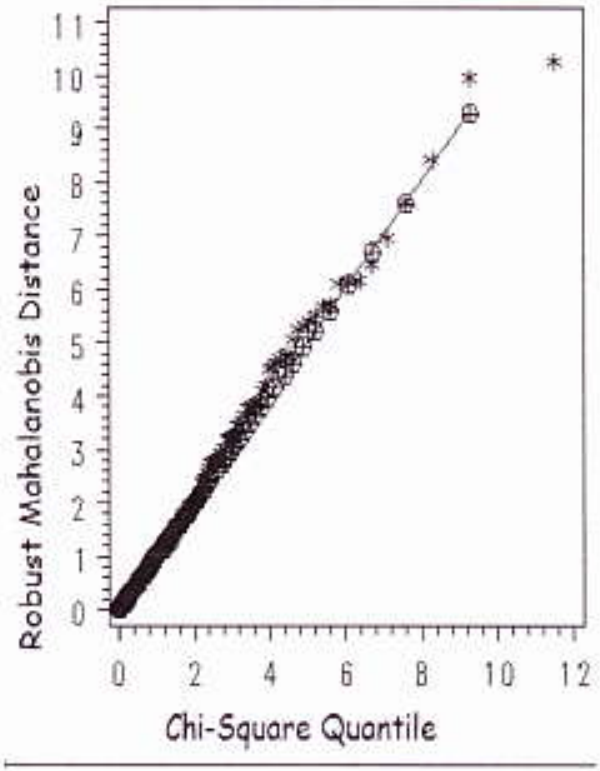

(b)

Gambar 1. Q-Q Plot antara Jarak Robust Mahalanobi lawan Kuantil Chi-Kuadrat

1 (a) terlihat bahwa ada beberapa titik yang outlier, dan ditunjang pula oleh hasil uji asumsi ketidak normalan multivariat data yang menyatakan tidak normal. Dengan menghapus sebanyak 14 titik pengamatan terpencil yaitu: hari ke-4, hari ke- 6 , hari ke-7, hari ke-34, hari ke-49, hari ke-60, hari ke-86, hari ke-89, hari ke-90, hari ke-96, hari ke-100, hari ke-112, hari ke-125, dan hari ke-126, maka Q-Q Plot antara Jarak Robust Mahalanobis lawan Kuantil Chi-Kuadrat bisa dilihat pada Gambar 1 (b). Dari Gambar 1 (b) terlihat bahwa sebaran titik-titik sudah mendekati garis lurus. Dengan ditunjang oleh penolakan terhadap uji asumsi ketidak normalan multivariat dan hasil pemeriksaan Q-Q Plot Gambar 1 (b) bisa disimpulkan bahwa data sudah berdistribusi normal multivariat.

\subsection{Pendugaan Parameter Model}

Mengingat ada 14 pencilan (outlier), maka total pengamatan tinggal 157 hari. Dengan demikian pendugaan parameter model dilakukan dengan mengambil matriks respon $\mathbf{Y}$ berukuran $(157 \times 2)$ yang berupa hasil produksi gula dan tetes. Sebagai variabel penjelas dari pengaruh fix diambil $\mathbf{X}=\left[\begin{array}{llllllll}1 & \mathbf{x}_{1} & \mathbf{X}_{21} & \mathbf{x}_{4} & \mathbf{X}_{5} & \mathbf{x}_{6} & \mathbf{x}_{7} & \mathbf{x}_{8}\end{array}\right]$ berukuran 
$(157 \times 8)$ dimana nilai vektor variabel telah dikurangi oleh meannya masing-masing dengan catatan bahwa vektor $\mathbf{x}_{21}$ adalah gabungan dari vektor $\mathbf{x}_{2}$ dan $\mathbf{x}_{3}$. Sedangkan untuk variabel pengaruh random diambil $\mathbf{Z}=\left[\begin{array}{llll}\mathbf{z}_{1} & \mathbf{z}_{2} & \mathbf{Z}_{3} & \mathbf{Z}_{4}\end{array}\right]$ berukuran $(157 \times 4)$ dengan nilai vektor variabel telah dikurangi oleh meannya masing-masing. Dengan bantuan perangkat lunak SAS Version 9.00 (Khattree dan Naik, 1999) mengambil prosedur proc mix dengan model $\operatorname{vec}\left(\mathbf{Y}^{T}\right)=\mathbf{X} \otimes \mathbf{I}_{2}$ dan bagian random $=\mathbf{Z} \otimes \mathbf{I}_{2}$ dari metode ML type terstruktur memberikan dugaan parameter sesuai dengan Latra, Linuwih, Purhadi, dan Suhartono (2010) antara lain; dugaan koefisien dari pengaruh fix $\mathbf{B}^{T}$ yaitu $\hat{\mathbf{B}}^{T}$ adalah,

$$
\dot{\mathrm{B}}^{T}=\left(\begin{array}{cccccccc}
682.43 & 0.07168 & 0.1026 & 0.03918 & 0.07101 & 0.1254 & 0.04421 & 0.06581 \\
3.9691 & 0.007444 & 0.01084 & 0.001506 & 0.005617 & 0.01030 & 0.001110 & 0.004100
\end{array}\right)
$$

dan dugaan koefisien dari pengaruh random $\mathbf{D}^{T}$ yaitu $\hat{\mathbf{D}}^{T}$ adalah,

$$
\hat{\mathbf{D}}^{T}=\left(\begin{array}{cccc}
2.66 \mathrm{E}-19 & 0 & 0.1149 & 0 \\
0 & 0 & 0 & 0
\end{array}\right)
$$

\subsection{Pengujian Hipotesis}

Pengujian hipotesis untuk memperoleh koefisien mana saja yang secara nyata berpengaruh dalam model dilakukan secara parsial terhadap semua komponen $\operatorname{vec}\left(\hat{\mathbf{B}}^{T}\right)$. Hipotesis yang digunakan adalah

$$
\begin{aligned}
& H_{0}: \beta_{i j}=0 \\
& H_{1}: \beta_{i j} \neq 0, i=1,2,3,4,5,6,7 ; j=1,2 .
\end{aligned}
$$

Daerah penolakannya adalah $|T|>\mathrm{t}_{290,0.025}$. Hasil pengujian disajikan dalam Tabel 1. dan terlihat bahwa variabel-variabel pengaruh fix yang berpengaruh nyata terhadap Y1 atau produksi gula adalah : X01 atau Intersep, X11 atau ATRSI - 1553, X21 atau ATRSIIl - 1322, X41 atau BTRSII - 4349, X51 atau BTRTI - 701.32749, X61 atau BTRTII - 3209, dan X71 atau TRM - 11544 dan tidak satupun variabel pengaruh fix berpengaruh terhadap $\mathrm{Y} 2$ atau produksi tetes. Artinya matriks koefisien dari $\mathbf{X}$ hanya satu kolom dengan kata lain matriks koefisien $\mathbf{X}$ singular berank 1, sehingga variabel-variabel ATRSI, ATRSII1, BTRSII, BTRTI, BTRTII, 
Tabel 1 Uji Koefisien Pengaruh Fix

\begin{tabular}{|c|c|c|c|c|c|}
\hline Efek & Estimasi & $\begin{array}{c}\text { Standard } \\
\text { Error }\end{array}$ & DF & Nilai $t$ & $\operatorname{Pr}>|t|$ \\
\hline X0I & 682.43 & 130.09 & 290 & 5.25 & $<.0001$ \\
\hline X02 & 3.9691 & 124.52 & 290 & 0.03 & 0.9746 \\
\hline $\mathrm{X} 11$ & 0.07168 & 0.008484 & 290 & 8.45 & $<.0001$ \\
\hline $\mathrm{X} 12$ & 0.007444 & 0.008475 & 290 & 0.88 & 0.3805 \\
\hline $\mathrm{X} 21$ & 0.1026 & 0.01211 & 290 & 8.47 & $<.0001$ \\
\hline$X 22$ & 0.01084 & 0.01209 & 290 & 0.90 & 0.3707 \\
\hline$\times 31$ & 0.03918 & 0.01494 & 290 & 2.62 & 0.0092 \\
\hline $\mathrm{X} 32$ & 0.001506 & 0.01473 & 290 & 0.10 & 0.9186 \\
\hline X41 & 0.07101 & 0.007272 & 290 & 9.76 & $<.0001$ \\
\hline $\mathrm{X} 42$ & 0.005617 & 0.007210 & 290 & 0.78 & 0.4365 \\
\hline$\times 51$ & 0.1254 & 0.01341 & 290 & 9.35 & $<.0001$ \\
\hline X52 & 0.01030 & 0.01286 & 290 & 0.80 & 0.4236 \\
\hline X6I & 0.04421 & 0.008894 & 290 & 4.97 & $<.0001$ \\
\hline X62 & 0.001110 & 0.006377 & 290 & 0.17 & 0.8619 \\
\hline X71 & 0.06581 & 0.005493 & 290 & 11.98 & $<.0001$ \\
\hline$X 72$ & 0.004100 & 0.005268 & 290 & 0.78 & 0.4371 \\
\hline
\end{tabular}

dan TRM berpengaruh aditif secara linier ke satu komponen respon $\mathbf{Y}$ pada model (Y1). Dengan catatan bahwa variabel ATRSIIl adalah gabungan dari variabel ATRSII dan BIBIT. Berdasarkan hasil uji parsial baik untuk koefisien pengaruh fix maupun untuk koefisien pengaruh random, memberikan hasil bahwa variasi-variasi nilai variabel yang secara nyata berpengaruh dalam model linier campuran multivariat adalah yang mempunyai hubungan model linier campuran univariat sebagai berikut,

$$
\begin{aligned}
\hat{\mathrm{Y}}_{1}= & -1059.41432+0.07168 \mathrm{ATRSI}+0.1026 \mathrm{ATRSII}+0.07101 \mathrm{BTRSII}+ \\
& 0.1254 \mathrm{BTRTI}+0.04421 \mathrm{BTRTII}+0.06581 \mathrm{TRM}+0.1149 \mathrm{BEL}
\end{aligned}
$$

Akan tetapi jika dilihat dari korelasi antara $\mathrm{Y} 1$ dan $\mathrm{Y} 2$ sebesar $75 \%$, maka di antara variabel respon terjadi multikolinieritas. Mengingat hanya ada dua variabel respon, maka antara keduanya mempunyai hubungan linier yang sangat kuat. Jadi apapun yang berpengaruh pada produksi gula juga akan berpengaruh pada produksi tetes dengan bentuk model yang sama. Faktor yang mempengaruhi hasil produksi gula dan tetes secara multivariat dari pengaruh fix adalah: variasi berat tebu rakyat 
kerja sama usaha lahan sawah untuk tanaman baru yang dikelola oleh PGCBS sebesar $7.2 \%$, variasi berat tebu rakyat kerja sama usaha lahan sawah untuk tanaman keprasan dan bibit yang dikelola oleh PGCBS $10.3 \%$, variasi berat tebu rakyat kerja sama usaha lahan sawah untuk tanaman baru yang dikelola oleh petani $3.9 \%$, variasi berat tebu rakyat kerja sama usaha lahan sawah untuk tanaman keprasan yang dikelola oleh petani $7.1 \%$, variasi berat tebu rakyat kerja sama usaha lahan tegal untuk tanaman baru yang dikelola oleh petani $12.5 \%$, variasi berat tebu rakyat kerja sama usaha lahan tegal untuk tanaman keprasan yang dikelola oleh petani $4.4 \%$, dan variasi berat tebu rakyat kerja mandiri $6.6 \%$; serta ada faktor dari pengaruh random adalah variasi berat belerang yang diambil dari bahan penunjang (bukan bahan untuk gula maupun tetes) sebesar $11.5 \%$.

\section{KESIMPULAN DAN SARAN}

Berdasarkan hasil pembahasan serta uraian dari terapan model linier campuran multivariat di Pabrik Gula Candi Baru Sidoarjo (PGCBS) Jawa Timur di atas dapat ditarik suatu kesimpulan yaitu:

Variabel respons hasil produksi gula dan tetes mempunyai hubungan linier yang sangat kuat dan kedua-duanya dipengaruhi oleh sebanyak tujuh faktor pengaruh fix, yaitu variasi berat tebu rakyat kerja sama usaha lahan sawah untuk tanaman baru yang dikelola oleh PGCBS sebesar $7.2 \%$, variasi berat tebu rakyat kerja sama usaha lahan sawah untuk tanaman keprasan dan bibit yang dikelola oleh PGCBS 10.3\%, variasi berat tebu rakyat kerja sama usaha lahan sawah untuk tanaman baru yang dikelola oleh petani $3.9 \%$, variasi berat tebu rakyat kerja sama usaha lahan sawah untuk tanaman keprasan yang dikelola oleh petani $7.1 \%$, variasi berat tebu rakyat kerja sama usaha lahan tegal untuk tanaman baru $12.5 \%$, variasi berat tebu rakyat kerja sama usaha lahan tegal untuk tanaman keprasan $4.4 \%$, dan variasi berat tebu rakyat kerja mandiri $6.6 \%$; serta ada satu faktor dari efek random yaitu variasi berat belerang yang diambil dari bahan penunjang (bukan bahan untuk gula maupun tetes) sebesar $11.5 \%$. 
Selanjutnya berdasarkan uraian di atas penulis juga mengajukan beberapa saran antara lain:

1. Perlu pengkajian lebih lanjut mengapa terjadi pengamatan yang terpencil (outlier).

2. Perlu pengkajian lebih lanjut untuk memperlakukan missing bagi data yang nilainya nol pada pengaruh fix sehingga analisisnya menggunakan unbalance data.

\section{DAFTAR PUSTAKA}

Christensen, R. (1991) Linear Models for Multivariate, Time Series, and Spatial Data, Springer-Verlag, New York.

Edward, Y. D. dan Allenby, G. M. (2003) Multivariate Analysis of Multiple Response Data, Journal of Marketing Research XL, 321-334.

Garson, G. D. (2008) Linear Mixed Models: Random Effects, Hierarchical Linear, Multilevel, Random Coefficients, and Repeated Measures Models, Linear Mixed Models: Statnotes, from North Carolina State University, Public Administration. Unpublished paper, 1-49.

Gupta, A. K., Harrar, S. W. dan Fujikoshi, F. (2006) Asymptotics for Testing Hypothesis in Some Multivariate Variance Components Model Under nonnormality, Journal of Multivariate Analysis 77, 148-178.

Hogg, R. V., McKean, J. W., dan Craig, A. T. (2005) Introduction to Mathematical Statistics, Pearson Education, Inc., Upper Saddle River, New Jersey.

Jiang, J. (2007) Linear and Generalized Linear Mixed Models and Their Applications, Springer Science + Business Media, LCC., New York.

Kalaian, H. A. dan Raudenbush, S. W. (1996) A Multivariate Mixed Linear Model for Meta-Analysis, Psychological Methods, 1(3), 227-235.

Khattree, R. dan Naik, D. N. (1999) Applied Multivariate Statistics withSAS' Software. SAS Institute Inc., Cary, NC., USA.

Kubokawa, T. dan Srivastava, M. S. (2002) Prediction in Multivariate Mixed Linear Models, Discussion Papers are a series of manuscripts in their draft form, 1- 
24, www.e.u-tokvo.ac.jp/cirje/research/dp/2002/2002cf780.pdf, diakses pada $04-05-2009$.

LaMotte, L. R. (2007) A Direct Derivation of the REML Likelihood Function, Statistical Papers 48, 321-327.

Latra, I N., Linuwih, S., Purhadi, dan Suhartono (2010) Estimation for Multivariate Linear Mixed Models, International Journal of Basic \& Applied Sciences I.JBAS-IJENS 10(06), 79-85.

Morrell, C. H., Pearson, J. D., dan Brant, L. J. (1997) Linear Transformations of Linear Mixed-Effects Models, The American Statistician 51(4), 338-343.

Muller, K. E. dan Stewart, P. W. (2006) Linear Model Theory: Univariate, Multivariate, and Mixed Models, John Wiley \& Sons, Inc., Hoboken, New Jersey.

Pan, J. dan MacKenzie, G. (2007) Modelling Conditional Covariance in the Linear Mixed Model, Statistical Modelling 7(1), 49-71.

Picard, F., Lebarbier, E., Budinská, E., dan Robin, S. (2007) Joint Segmentation of Multivariate Gaussian Processes using Mixed Linear Models, Statistics for Systems Biology Group, Research Report(5), 1-10.

Ratmanto (2008) Proses Pembuatan Gula (Sugar Factory Process), Unpublished Paper, www.PROSES PEMBUATAN GULA (SUGAR FACTORY PROCESS) htm, diakses pada $02-08-2009$.

Revitalisasi Pertanian, Perikanan, dan Kehutanan (2009) Prospek dan Arah Pengembangan Agribisnis: Tebu, Badan Penelitian dan Pembangan Pertanian, Jakarta. www.litbang.deptan.go.id/special/komoditas/b4tebu, diakses pada $26-02-2009$.

Samani, E. B. dan Ganjali, M. (2008) A Multivariate Latent Variable Model for Mixed Continuous and Ordinal Responses, World Applied Sciences Journal 3(2), 294-299. 
Sammel, M. D., Ryan, L. M., dan Legler, J. M. (1997) Latent Variable Models for Mixed Discrete and Continuous Outcomes, Royal Statistical Society B 59(3), $667-678$.

Schafer, J. L. dan Yucel, R. M. (2002) Computational Strategies for Multivariate Linear Mixed-Effects Models With Missing Values, Journal of Computational and Graphical Statistics 11(2), 437-457.

Serfling, R. J. (1980) Approximation Theorems of Mathematical Statistics, John Wiley \& Sons, Inc., New York.

Searle, S. R. (1997) Built-In Restrictions on Best Linear Unbiased Predictors (BLUP) of Random Effects in Mixed Models, The American Statistician 51(1), 19-21. 